\title{
Graves’ Disease as a Late Manifestation of Immune Reconstitution Syndrome after Highly Active Antiretroviral Therapy in an HIV-1 Infected Patient
}

\author{
Evelin Mingote ${ }^{1}$, Agustina Urrutia ${ }^{1}$, Alejandra Viteri ${ }^{2}$, Cristina Faingold ${ }^{1}$, Carla Musso ${ }^{1}$ \\ ${ }^{1}$ Department of Endocrinology and Metabolism, Doctor César Milstein Hospital, Buenos Aires, Argentine; ${ }^{2}$ Department of Infectol- \\ ogy, Doctor César Milstein Hospital, Buenos Aires, Argentine. \\ Email: evelinmingote@hotmail.com
}

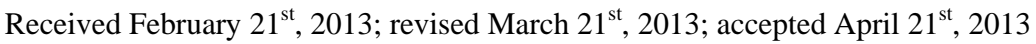

Copyright (c) 2013 Evelin Mingote et al. This is an open access article distributed under the Creative Commons Attribution License, which permits unrestricted use, distribution, and reproduction in any medium, provided the original work is properly cited.

\begin{abstract}
Context: Highly active antiretroviral therapy (HAART) inhibits the HIV replication and consequently increases CD4 levels and decreases viral load. This immune system improvement can trigger various immunological phenomena, entity called Immune Reconstitution Syndrome (IRS). Graves' disease is a late Immune Reconstitution consequence. Patient: We report the case of a 48 years old man with HIV infection who developed Graves' disease three years after he was on effective HAART because of the Immune Reconstitution Syndrome. At presentation he had a very low CD4 T-cell count (17 cells/ $\mu \mathrm{L})$. When he started HAART he presented a lipodystrophy syndrome. HAART was changed because of the persistent low CD4-T cells count (less than $100 \mathrm{cell} / \mu \mathrm{L}$ ). Afterwards serum lipid levels began to decrease and that was the first manifestation of Graves' disease, which was diagnosed when CD4 T-cells increased up to 343 cell/ $\mu \mathrm{L}$. Our patient developed Graves' disease 36 months after initiating effective HAART with protease inhibitors which was coincident with viral suppression and a rise of CD4 T cells. Conclusion: The most immunosuppressed patients with a CD4 T cell count less than 100 cells/ $\mu \mathrm{L}$ are at greatest risk for the development of Immune Reconstitution Syndrome after HAART initiation. We conclude that clinicians will have to consider the importance of the early diagnosis of thyroid disease to bring an adequate treatment.
\end{abstract}

Keywords: Graves’ Disease; Immune Reconstitution Syndrome; Highly Active Antiretroviral Therapy; HIV-1; Lipodystrophy Syndrome

\section{Introduction}

Highly active antiretroviral therapy (HAART) has been shown to decrease progression and mortality rates of human immunodeficiency virus (HIV) infection, leading to an increased incidence of metabolic abnormalities including insulin resistance, type 2 diabetes, hyperlipidaemia and abnormal body fat redistribution known as lipodystrophy syndrome [1,2]. Antiretroviral drugs association act by inhibiting the HIV replication and consequently increased CD4 levels and decreased viral load (VL). This immune system improvement can trigger various immunological phenomena entity called Immune Reconstitution Syndrome (IRS) [3,4]. This syndrome can be expressed in weeks or years after starting antiretroviral therapy and Graves' disease (GD) is a late IRS consequence [5].

\section{Patient}

The patient is a 48 years old man with HIV infection who was diagnosed 7 years earlier. At presentation he had a very low CD4 T-cell count of 17 cells $/ \mu \mathrm{L}$ and a viral load of 9100 copies $/ \mathrm{mL}$ (Table 1). His weight was $71 \mathrm{~kg}$ and his height was $169 \mathrm{~cm}$, normal body mass index and normal blood pressure. Laboratory assay showed total cholesterol (TC) $150 \mathrm{mg} / \mathrm{dl}$, alkaline phosphatase $180 \mathrm{U} / \mathrm{l}$ (0 - $240 \mathrm{U} / \mathrm{l})$ and glucose $87 \mathrm{mg} / \mathrm{dl}$. He was treated with lamivudine, zidovudine (nucleoside reverse transcriptase inhibitors, NRTI) and efavirenz (non-nucleoside reverse transcriptase inhibitors, NNRTI). A few months later we found an increase in TC $(226 \mathrm{mg} / \mathrm{dl})$ and a very high triglycerides (TG) levels $(793 \mathrm{mg} / \mathrm{dl})$ associated with a mild increase in CD4 T-cells count $(41 \mathrm{cell} / \mu \mathrm{L})$ and a decrease in VL (less than 50 copies/mL). He began life- 
Table 1. Laboratory results during the clinical course.

\begin{tabular}{|c|c|c|c|c|c|c|c|c|}
\hline & Jan & Oct & Oct & Oct 2009 & Oct & Jun & Dec & Normal \\
\hline & 2005 & 2005 & 2006 & 2009 & 2010 & 2011 & 2011 & Range \\
\hline $\mathrm{TC}, \mathrm{mg} / \mathrm{dl}$ & 150 & 226 & 205 & 63 & 198 & 123 & 191 & $<200$ \\
\hline $\mathrm{TG}, \mathrm{mg} / \mathrm{dl}$ & - & 793 & 140 & 73 & 94 & - & 160 & $<150$ \\
\hline Glu, mg/dl & 87 & - & 110 & 112 & 93 & 107 & 103 & $70-110$ \\
\hline CD4 (cells/ $\mu \mathrm{L}$ ) & 17 & 41 & 96 & 343 & 411 & 406 & 416 & $600-1200$ \\
\hline VL (copies/ml) & 9100 & $<50$ & $<50$ & $<50$ & $<50$ & $<50$ & $<50$ & $<50$ \\
\hline $\mathrm{TSH}, \mu \mathrm{UI} / \mathrm{ml}$ & - & - & - & $<0.03$ & $<0.03$ & $<0.03$ & 1.37 & $0.3-5$ \\
\hline FT4, ng/dl & - & - & - & 3.9 & 1.1 & 2 & - & $0.9-1.9$ \\
\hline ATPO (UI/ml) & - & - & - & 239 & - & - & - & $<40$ \\
\hline TSHRab\% & - & - & - & 45 & - & - & - & $<15$ \\
\hline
\end{tabular}

Jan 2005, HAART start; Oct 2005, lipodystrophy syndrome; Oct 2006, HAART change; Oct 2009, Graves’ disease diagnosis; -, not done; Glu, glucose.

style modifications without response, followed by fenofibrate. One year after HAART was initiated, even though he had TC and TG as expected, we observed a loss of body fat on the face, chest and buttocks associated with increased abdominal fat, gathering the lipodystrophy syndrome physical and metabolic characteristics associated with HAART. Because of the persistent CD4 T-cell count less than 100 cells/ $\mu \mathrm{L}$, HAART was changed to lopinavir and ritonavir (protease inhibitors, PIs) and he continued with lamivudine and zidovudine. He developed without complications until three years. At that moment, even though the immunological improvement due to an increase of CD4 T-cells until 343 cell $/ \mu \mathrm{L}$ and a decrease of VL less than 50 copies/ml, his TC was 63 mg/dl, HDL-c 32 mg/dl, LDL-c 16 mg/dl, TG 73 mg/dl, alkaline phosphatase $387 \mathrm{U} / \mathrm{l}$ and an impaired glucose tolerance. These values were associated with weight loss and high blood pressure, initially interpreted as a probable HAART toxicity. The antiretroviral therapy was changed to a new therapeutic with lower metabolic impact, atazanavir (PIs), emtricitabina , tenofovir (NRTI) and fenofibrate was discontinued with extremely low persistence of TC and LDL-c values. He had negative viral hepatitis serologies and abdominal ultrasound without pathological alterations. He then developed limb weakness, insomnia, and weight loss. Physical examination revealed tremors, right exophthalmos, enlarged thyroid gland and increase in heart rate. His thyroid-stimulating hormone (TSH) was less than $0.03 \mathrm{mUI} / \mathrm{ml}$, total thyroxine (TT4) was $24 \mu \mathrm{g} / \mathrm{dl}$ (4.5 - $13 \mu \mathrm{g} / \mathrm{dl})$, free thyroxine (FT4) was $3.9 \mathrm{ng} / \mathrm{dl}$, triiodo-thyronina (T3) was $7.2 \mu \mathrm{g} / \mathrm{dl}$ (0.8 $1.9 \mu \mathrm{g} / \mathrm{dl}$ ) and antithyroid antibodies (anti-thyroid peroxidase [anti-TPO] and thyrotropin receptor autoantibodies [TSHRab]) were positive. It is important to note that the first manifestation of GD in this patient was the change of lipid parameters.

The patient was treated with propanolol $40 \mathrm{mg}$ and methimazole $40 \mathrm{mg}$. There was no past personal or family history regarding thyroid disease. Two weeks later, he had an improvement of his symptoms and lately he normalized his blood pressure and lipid profile. The methimazole dose was progressively decreased until a low dose when he had clinical manifestation and biochemical data of a hyperthyroidism again. Even though the antithyroid dose was adjusted and his FT4 became normal in a short period of time, his TSH remained suppressed up to two years after he started antithyroid drugs.

\section{Discussion}

It is well known the association between HAART and lipodystrofy syndrome with a prevalence greater than $50 \%$ and with dyslipidaemia, [6] leading to high levels of TC, LDL-c and mainly TG [7]. Our patient developed that syndrome and lately serum lipid levels began to decrease as a consequence of the GD initially unknown. Since the change of lipid parameters were the opposite of what was expected in the lipodystrophy syndrome, diagnosis of GD should be taken into account as a differential diagnosis.

IRS may be triggered after initiation of HAART or after the change to a more active therapy as it was seen in our patient. The most immunosuppressed patients with a CD4 T cell count less than 100 cells/ml treated with the most potent regimens, particularly PIs, resulting in significant HIV viral load declines, are at greatest risk for the development of IRS after HAART initiation [8].

In 1998, Gilquin et al. reported the occurrence of autoimmune hyperthyroidism in 3 patients with HIV after 
16 - 22 months of beginning HAART [9]. Two years later, Jubault and Gilquin analyzed the relationship between thyroid autoantibodies, GD and immune restoration on HAART in five patients (median age, $41 \mathrm{yr}$ ). They found that GD diagnosis coincided with a great rise of the CD4 T-cell count. Anti-thyroid autoantibodies were absent before immune restoration with HAART and appeared 14 months after starting HAART. GD was diagnosed 18 months after the CD4 T-cell count had raised and 20 months after starting HAART [5].

Chen et al. published an observational study in 2005 in which 17 patients developed autoimmune thyroid disease (AITD) and GD was diagnosed in 15 of them. These patients were predominantly female (82\%), of black ethnicity (65\%) and the median age were 38 years. They were compared with a control group who started HAART during the same time and did not developed clinical AITD. The AITD group had a significantly lower mean baseline CD4 count compared with the control group (66.6 cells/ $\mu \mathrm{L}$ versus 218.8 cells/ $\mu \mathrm{L}$ ) and a higher rise in CD4 Tcells count (355.1 cells/ $\mu \mathrm{L}$ versus 199.6 cells $/ \mu \mathrm{L}$ ). More patients in the AITD group were severely compromised at baseline than controls. Memory CD4 T-cells increase a few weeks to months after commencement of HAART by redistribution from the lymphoid tissues, phase in which can appear opportunistic infections follow by a rise of naive CD4 $\mathrm{T}$ cells of thymic origin, from 6 months to years. All patients developed AITD in the phase of naive $\mathrm{T}$ cell reconstitution [10].

The inmunopathogenesis of GD after the substantial increased of T-cells because of HAART, might result from an acquired defect of central $\mathrm{T}$ cell tolerance resulting from thymus dysfunction [11], defects of peripheral $\mathrm{T}$ cell tolerance expressed by abnormal function of the $\mathrm{T}$ cell immunoregulatory receptor cytotoxic $\mathrm{T}$ lynphocyte antigen 4 (CTLA-4) [12,13] and "molecular mimicry" because of a structural similarity between microbial and self-antigens that could have a key role in activating autoreactive T cells [14,15]. GD after HAART in HIV patients may result from failure to delete auto-reactive $\mathrm{T}$ cell clones because of the intense regeneration in the thymus [11].

Patients with sustained virological responses to HAART had a rise of soluble CTLA4 that could compete with membrane-bound CTLA-4 for CD80/CD86, in later $\mathrm{T}$ lymphocytes activation phase, causing a reduction of inhibitory signal enhancing the immune response [12, 13].

Among the reported cases (Table 2) the mean age was 36.7 years, the mean CD4-T cells count increased from nadir to the development of GD was $394.5 \mathrm{cell} / \mu \mathrm{L}$ and the mean time from starting HAART to the diagnosis of GD was 26 months (range 9 - 53). All patients were treated with antithyroid drugs, some of them required I131 treatment lately and only a few were thyroidectomized [5,9-11,16-21]. In our case, radioablation therapy was not an option because of the exophthalmos presence and we decided to begin methimazole in spite of the aplastic anemia low risk.

Our patient developed GD 36 months after initiating effective HAART with protease inhibitors which was coincident with viral suppression and a rise of CD4 T

Table 2. Reported cases of Graves' disease after IRS.

\begin{tabular}{|c|c|c|c|c|c|c|c|}
\hline Cases & Mean & CD4 cell & Time to & & Treatment (cases No) & & Reference \\
\hline \multirow[t]{2}{*}{ No. } & Age & Change & GD & Antithyroid & $\mathrm{I}-131$ & Surgery & Year \\
\hline & (Years) & (Cells/ml) & (Months) & Drugs & & & \\
\hline 3 & 39 & $25-287$ & 18 & 3 & 1 & - & 1998, Gilquin \\
\hline 5 & 37 & $18-297$ & 20 & NR & NR & NR & 2000, Jubault \\
\hline 6 & 38 & $104-533$ & 20 & NR & NR & NR & 2004, Wong \\
\hline 1 & 39 & $0-600$ & 32 & 1 & 1 & - & 2004, French \\
\hline 15 & 39 & $45-430$ & 17 & 15 & - & - & 2005, Chen \\
\hline 5 & 43 & $11-291$ & 17 & 5 & - & 2 & 2006, Crum \\
\hline 1 & 27 & $12-623$ & 36 & 1 & - & - & 2006, Knysz \\
\hline 3 & NR & $0-410$ & 25 & 3 & 3 & - & 2006, Vos \\
\hline 2 & 30 & NR - 77 & 39 & 2 & 2 & - & 2007, Pinto \\
\hline 4 & 39 & $59-397$ & 37 & 4 & 1 & - & 2011, Rasul \\
\hline
\end{tabular}

NR, not reported; -, not done; GD, Graves’ disease; IRS, Immune Reconstitution syndrome. 
cells from less than 100 to 343 cells/ $\mu \mathrm{L}$, being that an infrequent but recognized late presentation of the Immune Reconstitution Syndrome in mostly immune suppressed HIV patients.

\section{Conclusion}

The most immunosuppressed patients with a CD4 T cell count $<100$ cells $/ \mathrm{ml}$ treated with the most potent regimens, particularly PIs, resulting in significant HIV viral load declines are at greatest risk for the development of IRS after HAART initiation [8]. Even though it is an uncommon manifestation of IRS, we think that Clinicians will have to consider the importance of the early diagnosis to bring an adequate treatment and to decrease the associated morbidity of Graves’ disease.

\section{REFERENCES}

[1] A. Carr, K. Samaras, D. J. Chrisholm and D. A. Cooper, "Pathogenesis of HIV-1-Proteasa Inhibitor Associated PeRipheral Lipodystrophy, Hyperlipidaemia and Insulin Resistance," Lancet, Vol. 352, No. 9144, 1998, pp. 18811883. doi:10.1016/S0140-6736(98)03391-1

[2] R. Singhania and D. Kotler, "Lipodystrophy in HIV Patients: Its Challenges and Management Approaches," HIV/AIDS-Research and Palliative Care, Vol. 3, 2011, pp. 135-143.

[3] M. A. French, M. Lenzo, M. John, S. Mallal, E. J. McKinnon, I. R. James, P. Price, J. P. Flexman and M. TayKearney, "Immune Restoration Disease after the Treatment of Immunodeficient HIV-Infected Patients with Highly Active Antiretroviral Therapy," HIV Medicine, Vol. 1, No. 2, 2000, pp. 107-115. doi:10.1046/j.1468-1293.2000.00012.x

[4] M. A. French, "HIV/AIDS: Immune Reconstitution Inflammatory Syndrome,” Clinical Infectious Diseases, Vol. 48, No. 1, 2009, pp. 101-107. doi:10.1086/595006

[5] V. Jubault, A. Penfornis, F. Schillo, B. Hoen, M. Izembart, J. Timsit, M. D. Kazatchkine, J. Gilkin and J. P. Viard, "Sequential Occurrence of Thyroid Autoantibodies and Graves' Disease after Immune Restoration in Severely Immunocompromised Human Immunodeficiency Virus1 Infected Patients,” The Journal of Clinical Endocrinology \& Metabolism, Vol. 85, No. 11, 2000, pp. 4254-4257. doi:10.1210/jc.85.11.4254

[6] K. Samaras, H. Wand, M. Law, S. Emery, D. Cooper and A. Carr, "Prevalence of Metabolic Syndrome in HIV-Infected Patients Receiving Highly Active Antiretroviral Therapy Using International Diabetes Foundation and Adult Treatment Panel III Criteria: Associations with Insulin Resistance,” Diabetes Care, Vol. 30, No. 2, 2001, p. 455.

[7] E. Fontas, F. van Leth, C. A. Sabin, N. Friis-Møller, M. Rickenbach, A. d'Arminio Monforte, O. Kirk, M. Dupon, L. Morfeldt, S. Mateu, K. Petoumenos, W. El-Sadr, S. de Wit, J. D. Lundgren, C. Pradier and Reiss, "Profiles in HIV-Infected Patients Receiving Combination Antiretroviral Therapy: Are Different Antiretroviral Drugs Associated with Different Lipid Profiles?” JID, Vol. 189, No. 6, 2004, pp. 1056-1074. doi:10.1086/381783

[8] Y. C. Manabe, J. D. Campbell, E. Sydnor and R. D. Moore, "Immune Reconstitution Inflammatory Syndrome: Risk Factors and Treatment Implications," JAIDS Journal of Acquired Immune Deficiency Syndromes, Vol. 46, No. 4, 2007, pp. 456-462. doi:10.1097/QAI.0b013e3181594c8c

[9] J. Gilquin, J. P. Viard, V. Jubault, C. Sert and M. D. Kazatchkine, "Delayed Occurrence of Graves' Disease after Immune Restoration with HAART,” Lancet, Vol. 352, No. 9119, 1998, pp. 1907-1908. doi:10.1016/S0140-6736(05)60398-4

[10] F. Chen, S. L. Day, R. A. Metcalfe, G. Sethi, M. S. Kapembwa, M. G. Brook, D. Churchill, A. de Ruiter, S. Robinson, C. J. Lacey and A. P. Weetman, "Characteristics of Autoimmune Thyroid Disease Occurring as a Late Complication of Immune Reconstitution in Patients with Advanced Human Immunodeficiency (HIV) Disease,” Medicine, Vol. 84, No. 2, 2005, pp. 98-106. doi:10.1097/01.md.0000159082.45703.90

[11] M. A. French, S. R. Lewin, C. Dykstra, R. Krueger, P. Price and P. J. Leedman, “Graves' Disease during Immune Reconstitution after Highly Active Antiretroviral Therapy for HIV Infection: Evidence of Thyroid Dysfunction," AIDS Research and Human Retroviruses, Vol. 20, No. 2, 2004, pp. 157-162. doi:10.1089/088922204773004879

[12] S. F. Stone, P. Price and M. A. French, "Dysregulation of CD28 and CTLA-4 Expression by CD4 T Cells from Previously Immunodeficient HIV-Infected Patients with Sustained Virological Responses to Highly Active Antiretroviral Therapy," HIV Medicine, Vol. 6, No. 4, 2005, pp. 278-283. doi:10.1111/j.1468-1293.2005.00307.x

[13] D. Saverino, R. Brizzolara, R. Simone, A. Chiappori, F. Milintenda-Floriani, G. Pesce and M. Bagnasco, "Soluble CTLA-4 in Autoimmune Thyroid Diseases: Relationship with Clinical Status and Possible Role in the Immune Response Dysregulation,” Clinical Immunology, Vol. 123, No. 2, 2007, pp. 190-198. doi:10.1016/j.clim.2007.01.003

[14] T. Kamradt and N. A. Mitchison, "Tolerance and Autoinmunity," The New England Journal of Medicine, Vol. 344, No. 9, 2001, pp. 655-664. doi:10.1056/NEJM200103013440907

[15] L. J. Albert and R. D. Inman, "Molecular Mimicry and Autoimmunity,” The New England Journal of Medicine, Vol. 341, No. 27, 1999, pp. 2068-2074. doi:10.1056/NEJM199912303412707

[16] K. H. Wong, W. S. Chow and S. S. Lee, "Clinical Hyperthyroidism in Chinese Patients with Stable HIV Disease," Clinical Infectious Diseases, Vol. 39, No. 8, 2004, pp. 1257-1259. doi:10.1086/424749

[17] N. F. Crum, A. Ganesan, S. T. Johns and M. R. Wallace, "Graves Disease: An Increasingly Recognized Immune Reconstitution Syndrome,” AIDS, Vol. 20, No. 3, 2006, pp. 466-469. doi:10.1097/01.aids.0000196173.42680.5f

[18] B. Knysz, M. Bolanowski, M. Klimczak, A. Gladysz and K. Zwolinska, “Graves' Disease as an Immune Recons- 
titution Syndrome in an HIV-1-Positive Patient Commencing Effective Antiretroviral Therapy," Case Report and Literature Review, Viral Immunology, Vol. 19, No. 1, 2006, pp. 102-107. doi:10.1089/vim.2006.19.102

[19] F. Vos, G. Pieters, M. Keuter and A. Van Der Ven, “Graves' Disease during Immune Reconstitution in HIV-Infected Patients Treated with HAART," Scandinavian Journal of Infectious Diseases, Vol. 38, No. 2, 2006, pp. 124-126. doi:10.1080/00365540500348960

[20] V. M. Pinto, Q. D. Iglesias, C. S. Corigliano, V. C. Ma- guiña, Z. J. Echevarria, C. S. Villena and R. C. Seas, “Graves Disease: Report of Two HIV Cases of Inmune Reconstitution Syndrome Following Highly Active Antiretroviral Therapy,” Revista Médica Herediana, Vol. 18, No. 4, 2007, pp. 218-221.

[21] S. Rasul, R. Delapenha, F. Farhat, J. Gajjala and S. Zahra, "Graves' Disease as a Manifestation of Immune Reconstitution in HIV-Infected Individuals after Initiation of Highly Active Antiretroviral Therapy,” AIDS Research and Treatment, 2011, 4 p. doi:10.1155/2011/743597 